\title{
Necrose retiniana aguda por presumível etiologia viral por herpes simples resultando em endoftalmite: Relato de caso
}

\author{
Acute retinal necrosis due to herpes simplex \\ resulting in endofthalmitis: Case report
}

Tatiana Tanaka1 , Fabrício Lopes da Fonseca², John Helal Junior ${ }^{3}$

\section{Resumo}

A necrose retiniana aguda é uma rara e devastadora retinite necrotizante, que pode ser causada pelo vírus herpes simples tipo 1 ou 2. Afeta tipicamente pacientes saudáveis de todas as idades. Este estudo é um relato de caso de um paciente de 18 anos, previamente hígido, que apresentou necrose aguda de retina por presumível etiologia viral por herpes simples, e descreve sua apresentação clínica e ultrassonográfica. Por não ter sido diagnosticado e tratado precocemente, a necrose retiniana aguda cumpriu sua história natural e evoluiu para um quadro compatível com endoftalmite.

Descritores: Síndrome de necrose retiniana aguda/etiologia; Ceratite herpética/complicações; Herpes simples/complicações; Endoftalmite/diagnóstico; Retina/patologia; Infecções oculares virais; Relatos de casos

\footnotetext{
'Médico Residente do Departamento de Oftalmologia do Hospital das Clínicas da Faculdade de Medicina da Universidade de São Paulo - USP - São Paulo (SP), Brasil;

${ }^{2}$ Médico Residente do Departamento de Oftalmologia do Hospital das Clínicas da Faculdade de Medicina da Universidade de São Paulo - USP - São Paulo (SP), Brasil;

${ }^{3}$ Médico Assistente do Setor de Retina do Departamento de Oftalmologia do Hospital das Clínicas da Faculdade de Medicina da Universidade de São Paulo- USP - São Paulo (SP), Brasil.
}

Trabalho realizado no Hospital das Clínicas da Faculdade de Medicina da Universidade de São Paulo - USP - São Paulo (SP), Brasil. 


\section{INTRODUÇÃO}

A necrose retiniana aguda (NRA) é uma rara e devastadora retinite necrotizante, que pode ser causada pelo vírus herpes simples (HSV) tipo 1 ou 2 ou pelo vírus Varicela Zoster (VZV) ${ }^{(1-2)}$. Afeta tipicamente pacientes saudáveis de todas as idades. Primeiramente descrita em 1971, por Urayama et al. ${ }^{(3)}$, pode afetar um ou ambos os olhos.

O prognóstico é relativamente sombrio, tendo em vista que $60 \%$ dos pacientes apresentam acuidade visual final abaixo de 20/400, em conseqüência de descolamento de retina, neuropatia óptica isquêmica e periflebite oclusiva ${ }^{(1-4)}$.

\section{Relato do caso}

Paciente de 18 anos, previamente hígido, sexo masculino, natural de Souto Soares (BA), procedente de São Paulo (SP), solteiro, ajudante de marceneiro, procurou o Pronto-Socorro Oftalmológico do Hospital das Clí- nicas da Faculdade de Medicina da Universidade de São Paulo com queixa de dor ocular de forte intensidade, embaçamento visual e edema bipalpebral no olho esquerdo há três dias. Há quatro dias notou moscas volantes no campo visual nasal superior do olho esquerdo $(\mathrm{OE})$. Há sete dias apresentou um episódio de febre não aferida, dor abdominal leve, e lesões com crostas hemáticas no lábio inferior. Relatava lesões labiais recorrentes há cinco anos e ausência de úlceras orais ou genitais. Negava antecedentes pessoais, oftalmológicos ou familiares importantes. Negava uso de drogas ilícitas ou relação sexual.

Ao exame oftalmológico apresentava, à ectoscopia, olho direito (OD) sem alterações e OE com hiperemia e edema bipalpebral (Figura 1a). Reflexo fotomotor sem alterações no OD e prejudicado no OE, sem restrições da motilidade ocular extrínseca. Acuidade visual (AV) de 20/20 no OD e de percepção de luz no OE.

À biomicroscopia observou-se OD sem alterações e OE com hiperemia e quemose conjuntival, edema
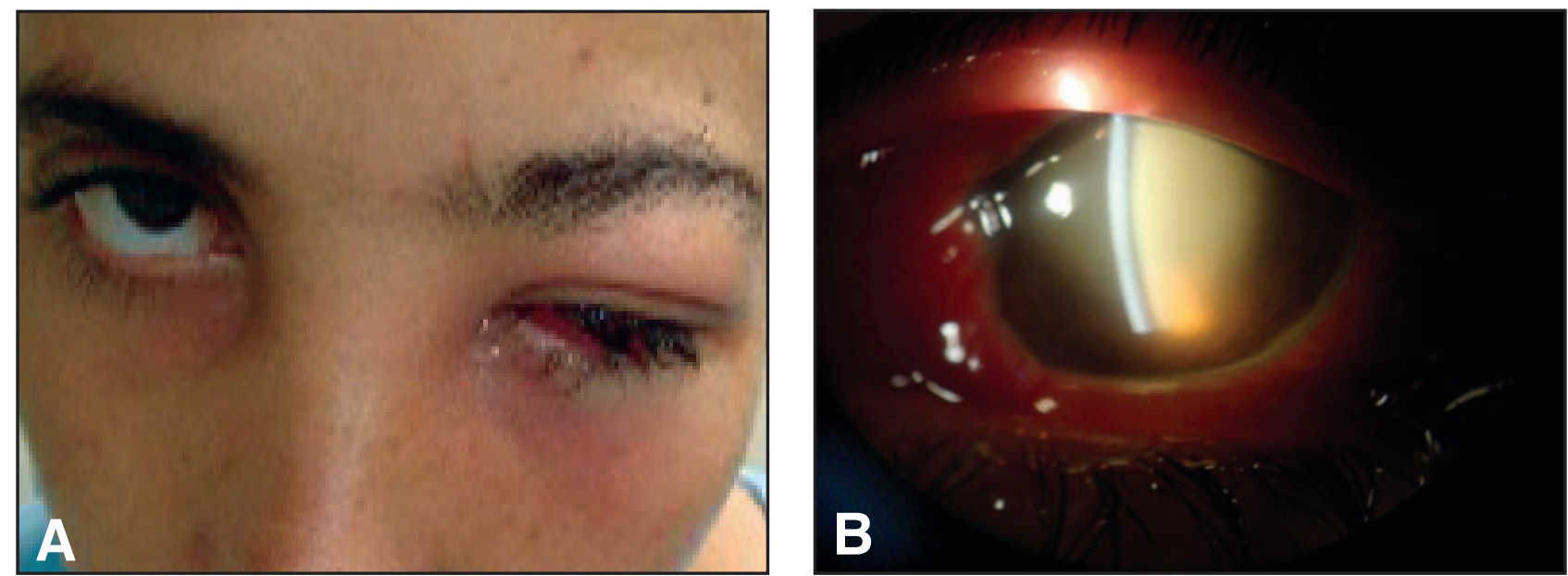

Figura 1: (a) edema bipalpebral no olho esquerdo; (b) câmara anterior com reação fibrinóide intensa
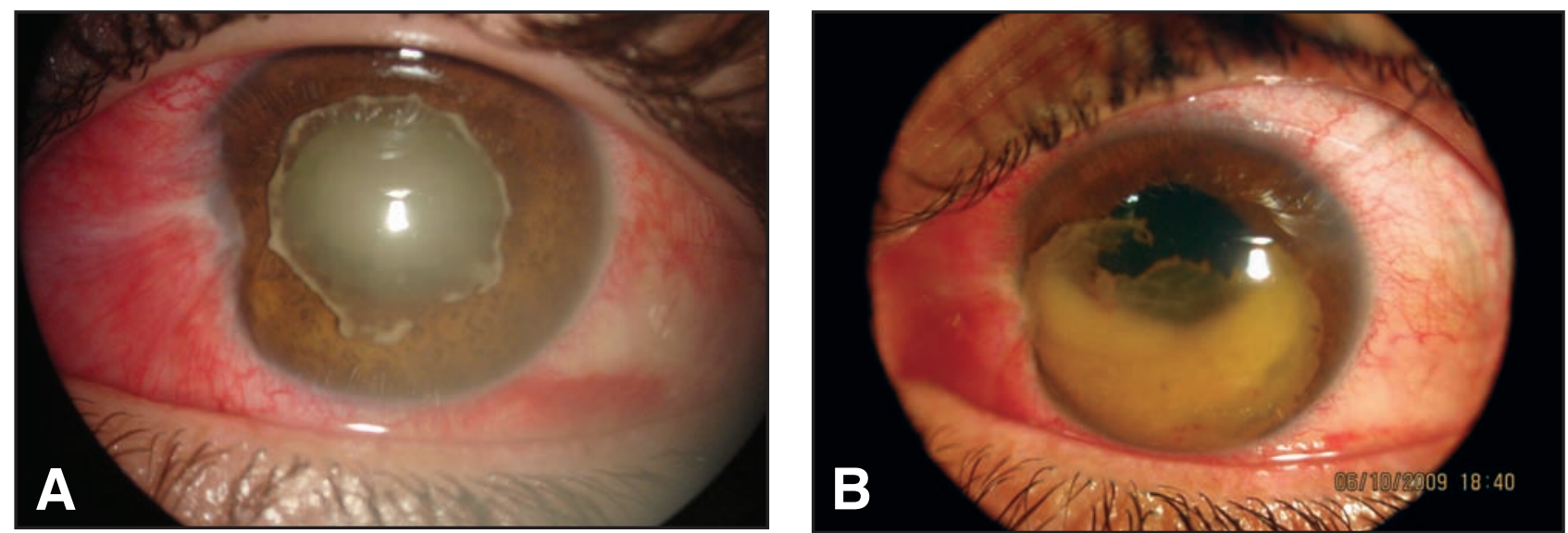

Figura 2: (a) fibrina na câmara anterior; (b) fibrina na câmara anterior pós-vitrectomia 

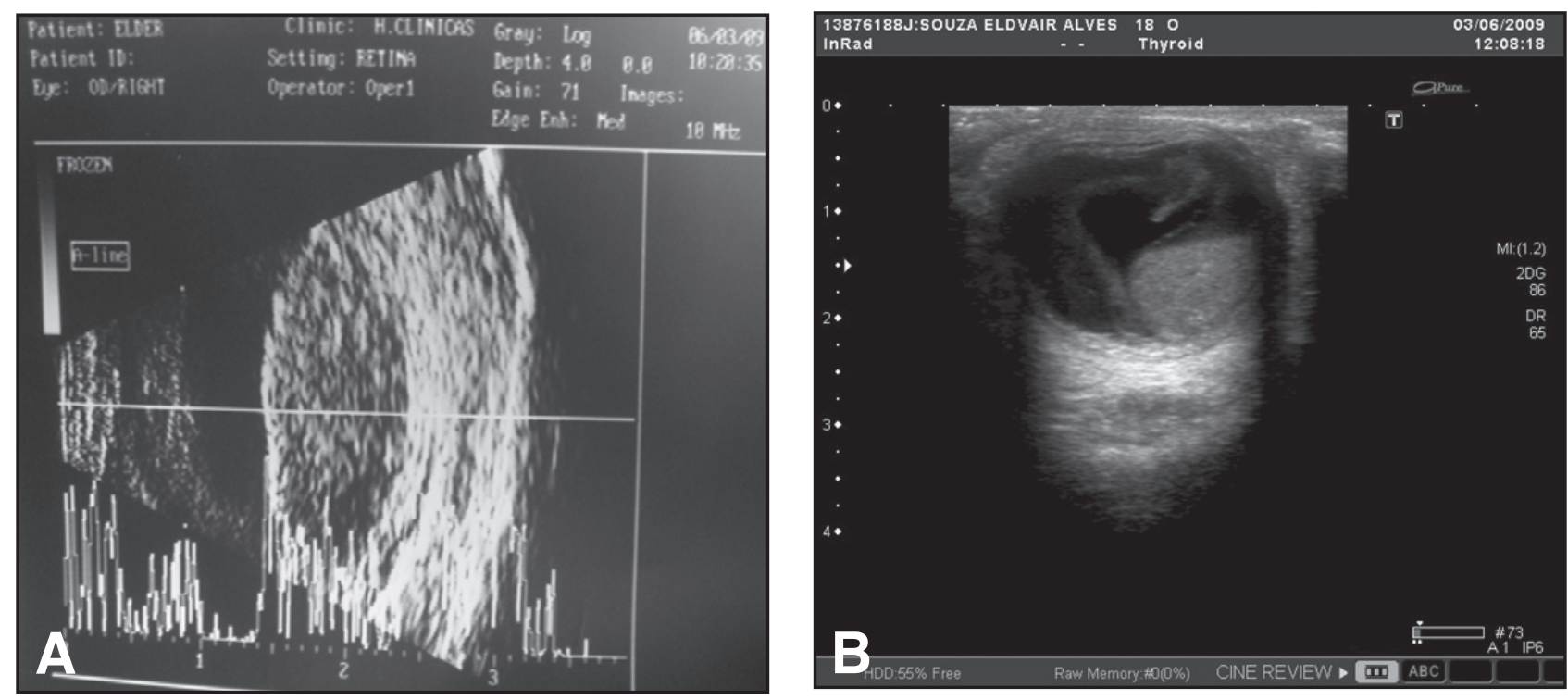

Figura 3: (a) Ultrassonografia do olho esquerdo: (b) Ultrassonografia com doppler do olho esquerdo

corneano 4+/4+, câmara anterior formada com reação fibrinóide intensa (Figura 1b e 2a). A fundoscopia do OD não apresentava alterações e a do OE não foi possível realizar.

A ultrassonografia do OE mostrou opacidades puntiformes finas e grosseiras na cavidade vítrea delimitada por imagem sugestiva de descolamento de retina total em todos os setores e imagem sugestiva de descolamento de coróide em L1 e L8, e presença de líquido subtenoniano (Figura 3 a).

Frente à hipótese diagnóstica de endoftalmite endógena, foi iniciada antibioticoterapia com Ceftriaxone $2 \mathrm{~g} / \mathrm{dia}$ e Clindamicina $2400 \mathrm{mg} / \mathrm{dia}$ via intravenosa. Como não houve melhora do quadro, optou-se por injeção intravítrea de Ceftazidima $(2 \mathrm{mg})$, Vancomicina (1 mg) e Dexametasona $(0,8 \mathrm{mg})$ no segundo dia de internação. Exames complementares (TC órbita e seios da face, USG abdome, raios-X de tórax, urina I, ecocardiograma, HMG, HMC) estavam dentro dos padrões de normalidade.

Na ultrassonografia com doppler (Figura 3b) foram evidenciados descolamento total de retina e descolamento de coróide temporal, com material líquido e espesso entre a coróide e a esclera, podendo corresponder à fibrina, e sem fluxo nos folhetos descolados da retina.

Foi realizada a Vitrectomia Via Pars Plana (VVPP) diagnóstica com 23 Gauge, em que foi visibilizada uma retina esfarelada com os vasos desnudos e ausência de sangramento, sugestivo de uma necrose de retina difusa. Foi coletado material para bacterioscopia, pesquisa de fungos, cultura e PCR para HSV,HVZ, toxoplasmose e citomegalovirus (CMV). Não

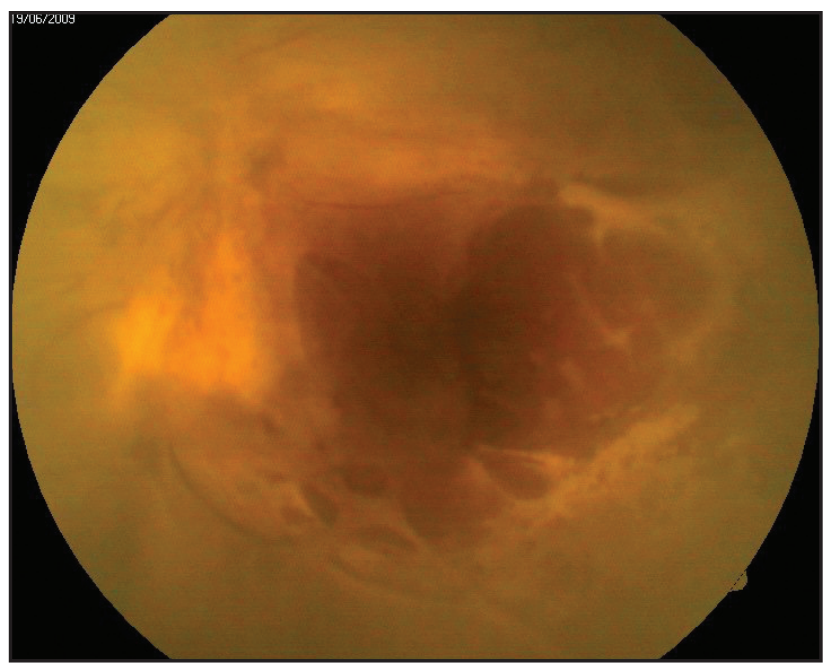

Figura 4: Retinografia do olho esquerdo

realizado reparo do DR ou biópsia por apresentar uma retina com necrose difusa.

O paciente foi submetido a exames sorológicos que incluiram: HIV negativo; CMV IgG positivo, IgM negativo; herpes IgM e IgG positivos; hepatite $\mathrm{C}$ negativo; PPD negativo; sífilis não reagente.

No material colhido no intraoperatório não houve crescimento de bactérias; pesquisa de fungo negativa; PCR para HSV I/II, HZV, toxoplasmose e CMV negativos.

Após esses resultados, estabeleceu-se o diagnóstico de necrose retiniana aguda por vírus herpes simples, resultando em endoftalmite, sendo instituído tratamento com Aciclovir via intravenosa, na dose de $10 \mathrm{mg} / \mathrm{kg}$ a cada $8 \mathrm{~h}$ por 14 dias, seguido por terapia via oral $(800 \mathrm{mg}$ 
por dose, 5 vezes ao dia), ao menos por 6 semanas.

Ao exame oftalmológico, após término do tratamento, apresentava à ectoscopia OD e OE sem alterações. A pressão intraocular do OD era $14 \mathrm{mmHg}$ e do $\mathrm{OE}$ era $02 \mathrm{mmHg}$. A AV do OD era 20/20 e do OE era sem percepção luminosa. À biomicroscopia do OE, conjuntiva calma, córnea LBT, CAF com reação de câmara anterior $4+/ 4+$ e afacia (Figura 2b). Ao fundo de olho, OD sem alterações e $\mathrm{OE}$ com palidez de retina, roturas retinianas, sem visibilização dos vasos (Figura 4).

\section{DısCuSSÃO}

A NAR é rara e devastadora. É mais observada em pacientes imunocompetentes, mas ocasionalmente ocorre em pacientes imunocomprometidos ${ }^{(5)}$.

A NAR é duas vezes mais comum em homens do que em mulheres. É uma doença bifásica, que tende a ser causada pelo HSV em pacientes jovens e pelo VZV em indivíduos mais velhos. Há associação de encefalite herpética ou herpes neonatal com NAR, além de associação com o uso de corticóide sistêmico até 2 meses antes do aparecimento da NAR, com trauma e com cicatrizes de coriorretinite ${ }^{(4)}$. Alguns pacientes tem história de encefalite por HSV, muitos anos antes de desenvolverem NAR, sendo que ocasionalmente a encefalite e NAR se desenvolvem simultaneamente ${ }^{(1)}$.

Em casos em que a relação temporal entre a infecção herpética clínica e a NAR é observada, pode-se presumir que o agente seja o vírus herpes simples ${ }^{(5)}$, como ocorreu no caso relatado, em que houve manifestação clínica de herpes labial, sendo seguido após quatro dias da manifestação ocular da NAR.

Outros agentes que estão envolvidos na patogênese da NAR são os vírus da varicela zoster, do Epstein-Barr e do $\mathrm{CMV}^{(5)}$.

A apresentação inicial é unilateral e varia de acordo com a gravidade. Alguns pacientes desenvolvem perda visual em alguns dias, enquanto outros têm início insidioso, com sintomas visuais leves, tais como moscas volantes ${ }^{(1-6)}$.

Como sinais clínicos, têm-se uveíte anterior granulomatosa, vitreíte, periarterite periférica ou necrose retiniana. Neovascularização e hemorragia vítrea secundária podem ocorrer ${ }^{(1-5)}$.

A Associação Americana de Uveíte publicou critérios diagnósticos para NAR, com características clínicas que incluem um ou mais focos de necrose de retina, com esmaecimento das bordas na periferia; progressão rápida da doença na ausência de tratamento; evidência de vasculopatia oclusiva com envolvimento arteriolar; e proeminente reação inflamatória no vítreo e câmara anterior ${ }^{(7)}$.

As lesões agudas resolvem-se em 6 a 12 semanas, resultando em retina necrótica transparente com bordos hiperpigmentados ${ }^{(1)}$.

Embora o diagnóstico de NAR seja clínico na maioria dos casos, a confirmação etiológica é realizada pela reação em cadeia da polimerase (PCR), para pesquisa viral ou anticorpos antivirais no humor aquoso ou no vítreo $^{(2,5,6)}$. A paracentese da câmara anterior para obter o humor aquoso é um procedimento seguro e menos invasivo em relação às técnicas de biópsia do vítreo. Walters et al. recomendam análise de amostras do aquoso em pacientes com uveítes atípicas ou suspeita de retinite viral ${ }^{(6)}$. Em estudo retrospectivo de 12 casos realizada por Tran et al., o DNA do virus herpes simples tipo 2 foi detectado em todos os pacientes ${ }^{(4)}$. Lau et al. tiveram PCR falsonegativo em $11,1 \%$ dos casos estudados ${ }^{(5)}$. Em nosso relato, obtivemos PCR negativo para herpes simples tipos $1 \mathrm{e}$ 2, toxoplasmose e CMV em amostra de material da câmara anterior coletado no intraoperatório, apesar de encontrarmos IgM e IgG positivos para vírus herpes ao estudo sorológico do paciente.

Duker et al. realizaram relato de caso de paciente de 22 anos que apresentou necrose aguda de retina em que foi detectado títulos séricos de vírus herpes simples tipo 1 na biópsia de vítreo. Uma das explicações para o resultado positivo seria por se tratar de um caso de infecção primária pelo vírus herpes simples, enquanto nas reativações esse achado torna-se mais difícil, devido aos baixos títulos séricos ${ }^{(8)}$.

Neste caso, a VVPP foi essencial para o diagnóstico, pela observação da retina com aspecto necrótico e oclusão vascular difusa. Embora pouco utilizada, a ultrassonografia ocular com doppler mostrou-se útil por evidenciar ausência de fluxo sanguíneo na retina descolada, fortalecendo a hipótese de NAR.

A menos que o paciente receba tratamento apropriado, o outro olho é acometido em $30 \%$ dos casos, num intervalo de cerca de 2 meses, embora em alguns pacientes esse tempo possa ser maior ${ }^{(1)}$.

O tratamento preconizado é realizado com Aciclovir, inicialmente intravenoso, na posologia de $10 \mathrm{mg} / \mathrm{kg} / \mathrm{dia}$ a cada 8 horas por 14 dias, seguida por administração via oral de $800 \mathrm{mg}$ da droga/dose, 5 vezes ao dia, por 6 - 12 semanas ${ }^{(1,2,5,6,9)}$. Para a reação de câmara anterior, são utilizados colírios de corticosteróide e cicloplégico/ midriático ${ }^{(9)}$.

Esse esquema pode acelerar a resolução das lesões retinianas agudas e reduzir o risco de envolvimento do outro olho, mas não previne descolamento da retina. Em alguns estudos, o tratamento com aciclovir reduz a taxa de envolvimento do outro olho de $64,9 \%$ para $24,7 \%$ em 2 anos, sendo que o efeito protetor é mais efetivo nas 14 primeiras semanas ${ }^{(6)}$. Alguns pacientes 
podem sofrer recidivas e a terapia a longo prazo pode ser necessária.

Emerson et al., em estudo intervencionista de 4 casos com terapia via oral com valaciclovir, famciclovir e corticoide oral e tópico, obteve resultados efetivos em eliminar sinais e sintomas da doença. Porém, estudos adicionais são necessários para avaliar se esse regime é tão efetivo quanto aciclovir via endovenosa no tratamento inicial da $\mathrm{NAR}^{(2)}$.

Tibbets et al. ${ }^{(10)}$ em estudo retrospectivo compararam o prognóstico de pacientes com necrose retiniana aguda tratados com aciclovir em relação a pacientes tratados com novas terapias antivirais (valacyclovir e famciclovir). Observaram evoluções semelhantes com ambas terapias e concluíram que o prognóstico dos pacientes com NAR geralmente é ruim.

Esteróides sistêmicos podem ser iniciados 24 horas depois de instituída a terapia antiviral, e geralmente são indicados em casos graves, especialmente os que mostram envolvimento do nervo óptico ${ }^{(1,6)}$. Altas doses de corticosteróides diminuem a inflamação intraocular.

Lau et al. recomendam fotocoagulação profilática para reduzir o risco de descolamento de retina secundário $^{(5)}$. Walters et al. também recomendam a fotocoagulação profilática, uma vez que reduziu a taxa de descolamento de retina em $67 \%$ no grupo não tratado em relação a $17 \%$ no grupo tratado ${ }^{(6)}$. O uso do laser não reduz a progressão da retinite, e repetidas sessões de fotocoagulação são necessárias. Park et al. ${ }^{(11)}$ consideraram que as questões sobre profilaxia com laser pode influenciar no risco de descolamento de retina, depender do grau de retinite e vitreíte e necessita de estudos multicêntrico randomizado prospectivo.

A VVPP é indicada para a hemorragia vítrea densa secundária a neovascularização ou descolamento de retina. No presente caso, foi indicada VVPP diagnóstica, visto que, em decorrência da falta de tratamento inicial, a NAR cumpriu sua história natural e evoluiu para o quadro compatível com endoftalmite.

\section{Conclusão}

Pelo presente relato, ressalta-se a importância da anamnese, dos sinais e sintomas extraoculares e do conhecimento da história natural da afecção, fatores esses que embasam o diagnóstico, a despeito da apresentação clínica tardia a dificultar a semiologia ocular.

\section{Abstract}

The acute retinal necrosis is a rare and devastating necrotizing retinitis, which can be caused by the herpes simplex virus type 1 or 2. It typically affects healthy patients of all ages. This study report a case of 18 year-old healthy male patient, with the the diagnosis of the acute retinal necrosis due to herpes simplex, and presents its clinical and ultrassonographic features. The acute retinal necrosis results in endofthalmitis because of lack of early diagnosis and therapy.

Keywords: Retinal necrosis syndrome, acute/ etiology; Keratitis, herpetic/complications; Herpes simplex/complications; Endophthalmitis/diagnosis; Retina/patology; Eye infections, viral; Case reports

\section{ReFERÊNCIAS}

1. Kanski JJ. Oftalmologia clínica: uma abordagem sistemática. 6a ed. Rio de Janeiro: Elsevier; 2008

2. Emerson GG, Smith JR, Wilson DJ, Rosenbaum JT, Flaxel CJ. Primary treatment of acute retinal necrosis with oral antiviral therapy. Ophthalmology. 2006;113(12):2259-61.

3. Urayama A, Yamada N, Sasaki T. Unilateral acute uveitis with periarteritis and detachment. Jpn J Clin Ophthalmol. 1971;25:607-19.

4. Tran TH, Stanescu D, Caspers-Velu L, Rozenberg F, Liesnard C, Gaudric A, et al. Clinical characteristics of acute HSV-2 retinal necrosis. Am J Ophthalmol. 2004;137(5):872-9

5. Lau GH, Missotten T, Salzmann J, Lightman SL. Acute retinal necrosis features, management, and outcomes. Ophthalmology. 2007;114(4):756-62.

6. Walters G, James TE. Viral causes of the acute retinal necrosis syndrome. Current Opin Ophthalmol. 2001;12(3):191-5.

7. Holland GN. Standard diagnostic criteria for the acute retinal necrosis syndrome. Executive Committee of the American Uveitis Society. Am J Ophthalmol. 1994;117(5):663-7.

8. Duker JS, Nielsen JC, Eagle RC Jr, Bosley TM, Granadier R, Benson WE. Rapidly progressive acute retinal necrosis secondary to herpes simplex virus, type 1 . Ophthalmology. 1990;97(12):1638-43.

9. Orefice F. Uveite clínica e cirurgia. Rio de Janeiro: Cultura Médica; 2000. Vol. 1.

10. Tibetts MD, Shah CP, Young LH, Duker JS, Maguire JI, Morley MG. Treatment of acute retinal necrosis. Ophthalmology. 2010;117(4):818-24.

11. Park JJ, Pavesio C. Prophylactic laser photocoagulation for acute retinal necrosis. Does it raise more questions than answers? Br J Ophthalmol. 2008;92(9):1161-2.

\section{Endereço para correspondência: \\ A/C Tatiana Tanaka}

R. Dr. José Rodrigues Alves Sobrinho, n⿳0150 - Apto.

142 - Monet - Alto de Pinheiros

CEP 05466-040 - São Paulo (SP)- Brasil

Tel: (11) 9607-9335

Fax (11) 4613-6000

E-mail: tatitanaka@hotmail.com 